\title{
EL CONGRESO DE MANILA PROGRAMA LA ACTUACION DE LA UNION INTERNACIONAL. DE CIUDADES Y PODERES LOCALES
}

$352: 341.12$

por

\section{Carlos-Enrique Ruiz del Castillo y de Navascués}

Secretario técnico del Centro de Cooperación Intermunicipal del Instituto de Estudios de Administración Local

SUMARIO: I. ANTECEDENTES.-II. EL PROGRAMA QUINQUENAL.

\section{ANTECEDENTES}

En el mes de febrero de 1979 tuvo lugar el Congreso anual de la Unión Internacional de Ciudades y Poderes Locales, número 24 de los celebrados por la Asociación y acogido esta vez por la ciudad hermana de Manila, en las entrañables Islas Filipinas.

No ha de extrañar que con sesenta y cinco años de antigüedad, las reuniones mundiales hayan sido solamente las 24 señaladas. Los primeros balbuceos de la Unión, las dificultades impuestas por las guerras y otros acontecimientos de repercusión internacional y la propia programación bienal de los Congresos motivan que éstos no coincidan en número con la «edad» de la Unión.

Esta institución internacional fue configurada en 1914 como una organización profesional apolítica de Poderes locales y de ciudades, con la finalidad de reforzar facultades y medios de las autoridades locales con el objetivo último de mejorar tal tipo de administra- 
ción. Los funcionarios locales se enfrentan actualmente con problemas cuya magnitud crece pareja con su complejidad. Esta doble realidad exige de aquéllos una información y una formación que rebasa las técnicas de su especialidad y tienen que apoyarse, por ello, en los conocimientos y experiencias de otros profesionales de la Administración local, tanto de sus respectivos países como del medio internacional.

Admitido este punto de partida y comprendida la ineludible exigencia de abordar los medios que provean a la mayor eficacia de la gestión local, el Consejo de la Unión Internacional de Ciudades y Poderes Locales ha aprovechado el Congreso de Manila para discutir, de la misma forma que lo ha hecho el Comité Ejecutivo, las orientaciones que deben catalizar la actividad de la Unión en los próximos años.

Así ha nacido el Programa quinquenal, que recoge un conjunto de directrices y prioridades que resumen aspiraciones y criterios de los miembros de la Unión, una vez tratados en el Comité Ejecutivo $y$ en el Financiero.

La exigencia inmediata de la puesta en marcha del Programa quinquenal es la elevación de la cuota de los miembros de la Unión en un 10 por 100 y el estudio de la situación financiera de aquélla. Se ha llegado a la conclusión de que de momento es conveniente no modificar el sistema de cálculo de las aportaciones de los miembros, por lo que se mantiene el actual sistema, si bien con la referida elevación de las cuotas.

\section{EL PROGRAMA QUINQUENAL}

Decidida la Unión Internacional de Ciudades y Poderes Locales a ampliar los servicios de que se benefician sus miembros, y recogido el deseo de los funcionarios locales de formar parte de una organización profesional internacional que defienda las competencias del Poder local, el órgano escrito de la Unión (1) da cuenta de que el plan de acción de ésta se propone crear una especie de bolsa de información, asegurar un servicio de formación de funcionarios locales y constituirse en portavoz de los Municipios en las convenciones internacionales.

(1) IUla Nouverles: La Haya (Holanda), abril de 1979, vol. 13, núm. 4. 
Así, el Plan quinquenal comprende los trece puntos fundamentales que a continuación se enumeran:

1. Impulso del órgano escrito IULA NOUVELLES. Con el fin de facilitar una información más concreta sobre las estructuras, legislación, actividades e innovaciones de las Entidades locales, la actual edición en lengua inglesa de IULA NOUVELLES - que es un cuadernillo mensual de cuatro o seis páginas en tamaño holandesava a convertirse en revista. Su contenido será enriquecido con importantes resúmenes de las organizaciones internacionales y promoverá la transferencia de tecnologías. Las ediciones alemana y francesa del actual formato de IULA NOUVELLES no sólo serán mantenidas, sino que, al fin, se verán completadas con una nueva versión en lengua española. Hay que felicitarse de que los responsables de IULA NOUVELLES hayan apreciado - aunque tarde- la gran audiencia y el amplio protagonismo de los pueblos de la estirpe española en las tareas de la Administración local.

2. Organización de reuniones internacionales. A lo largo del próximo quinquenio la Unión Internacional de Ciudades y Poderes Locales organizará conferencias en todas las grandes Regiones del mundo, al margen de los Congresos generales bienales, cuyo tema estará referido a las dificultades concretas de la Región que acoja a los reunidos. Los temas de actualidad serán tratados en seminarios a los que aportarán su colaboración la Organización de Naciones Unidas y otras organizaciones internacionales.

3. Cursos de formación para los funcionarios locales de Naciones en vias de desarrollo. El programa actual de formación para funcionarios superiores de Naciones en la situación indicada, y que consta de dos o tres cursos organizados cada año en Europa, quedará completado con otros cursos que radicarán precisamente en las indicadas Naciones.

4. Reuniones del tipo de colegio de funcionarios locales para Europa y América del Norte. El Programa quinquenal incluye un proyecto de reuniones breves - tan sólo habrán de durar dos o tres días- con el propósito de congregar a funcionarios locales con responsabilidad de mando, dada su jefatura sectorial, quienes tendrán ocasión, así, de exponer sus problemas, de aportar sus soluciones y de contrastar su perspectiva personal con las tendencias e iniciativas nuevas. Estas reuniones serán unas de las mejores ocasiones 
de enriquecer la propia formación teórica y práctica, con las experiencias de colegas que han afrontado similares situaciones.

5. Refuerzo de los contactos con las organizaciones internacionales. En los programas de actuación de varias organizaciones gubernamentales de ámbito internacional, han sido incluidos el estudio y tratamiento de problemas de administración rural y urbana. No corresponde únicamente a los Poderes centrales la decisión en este campo, ya que las Regiones y las Entidades de menor dimensión, incluidos los Municipios minúsculos que muchas veces soportan el problema, y con una gravitación directa, tienen algo o mucho que decir. Por no invocar más que dos ejemplos, piénsese en la terrible descompensación que significa para un pequeño núcleo rural de playa o de montaña, el aluvión poblacional que desahoga en él sus ocios estivales y que multiplica por dos, por cinco o por diez el número de habitantes. O piénsese en esa industria que ha elegido un pequeño Municipio para radicar su actividad contaminante y congestiva desde el punto de vista del medio humano que requiere, o del de los aprovisionamientos, depósito y circulación de materias primas o manufacturadas: es decir, el precio (deterioro ambiental) pagado por el progreso material que aporta la industrialización (2).

Pues bien, la Unión Internacional de Ciudades y Poderes Locales ha querido incluir en su Programa quinquenal una forma de relacionar a las administraciones locales, constituyéndose en su portavoz a la hora de discutir en la esfera internacional las dificultades que los medios rural y urbano experimentan en relación con el medio ambiente. Al mismo tiempo, la Unión reforzará sus contactos con los órganos profesionales interesados en este tipo de inconvenientes que obstaculizan una grata y normal evolución de los asentamientos humanos.

6. Incremento de la actividad en Europa. El Programa incluye, entre las actividades de la Unión Internacional, la intensificación de sus contactos con la Comunidad Económica Europea y de la información sobre sus actividades, para que los Poderes locales afectados puedan potenciar y hacer valer su influencia en la etapa de la predecisión. Para lograrlo, la Unión tratará de que ese estrechamiento de relaciones con la Comunidad Económica Europea no sea

(2) Es, en síntesis, el argumento del Primer Ministro sueco Olaf Palme al recibir en su patria en 1972 a los delegados en la Conferencia de las Naciones Unidas sobre el Medio Ambiente Humano. Vid. Europa Magazine, abril de 1972, citado por Cliff TANDY en aIndustria y paisaje», Madrid, IEAL, 1979, pág. 1. 
motivo de dar pasos en falso, ni de malograr esfuerzos: la utilidad detie estar en todo caso marcada por la racionalidad de los medios adoptados. En este aspecto, la Unión se verá sujeta a una cuidadosa atención de las posibilidades de establecimiento de sus contactos.

7. Intensificación de la comunicación con las Naciones en evolución. El Comité Ejecutivo de la Unión Internacional de Ciudades y Poderes Locales ha creado un Comité ad hoc especializado en el estudio de los medios aconsejables para aumentar los contactos de la Unión, y también sus actividades, cerca de aquellas Naciones que están en proceso evolutivo para mejorar su nivel económico y social.

8. Apoyo al asociacionismo de los gestores locales. El Programa quinquenal se propone, igualmente, apoyar la formación y el refuerzo de las diversas asociaciones de Poderes locales. Se trata, en definitiva, de cumplir la finalidad de la Unión, que no es otra sino la de allegar soluciones y estimular a las administraciones locales, aliviándolas en su quehacer de cada día.

9. Establecimiento de núcleos regionales. Dentro de la línea del tratamiento unitario de los grandes problemas, está prevista la creación de puntos de apoyo en diferentes partes del mundo, a guisa de primer paso para la regionalización, como estadio intermedio ideal en que se combinen y contrapesen el Poder central y los Poderes locales, en pos de una obra de eficacia y de validez general.

10. Universalidad de lo local. La Unión pretende dar audiencia y tratamiento —en el ámbito de su actividad, como es lógicoa los problemas locales de todo género y de toda procedencia, sin distinción de clases o categorías de núcleos locales, comprendiendo en éstos a las mismas Regiones metropolitanas.

11. Publicaciones. Ha quedado expuesto el nuevo tratamiento que la Unión imprimirá a su órgano mensual escrito de comunicación. Su labor editorial seguirá próxima a las obras e informes referidos a la Administración local. Es conocida la publicación de monografías, tratadas con aportación de los miembros de la Unión, así como de documentos que recogen los debates y conclusiones de los Congresos que viene celebrando.

12. Biblioteca. El Programa se propone divulgar los fondos de la Biblioteca de la Unión para lograr la máxima utilización por parte de sus miembros. 
13. Relaciones públicas. Finalmente, existe el propósito de intensificar y estrechar las relaciones de la Unión Internacional de Ciudades y Poderes Locales, tanto con la prensa como con el público en general. El tantas veces y generalmente invocado sistema de puertas abiertas no puede sino beneficiar a la Unión y a sus adheridos, ya que una de las claves de su funcionamiento es precisamente la de la comunicación y el intercambio, que son los dos pilares que proveen a la información, que es la piedra angular en la formación de las decisiones. Y la Administración local no es más que eso: un continuo proceso de decisión.

Séale permitido al cronista, para terminar, hacer una alusión a uno de los acuerdos del Comité Ejecutivo, adoptado en el 24 Congreso de Manila: España, en unión de Pakistán, ha sido invitada a designar representantes en el citado Comité Ejecutivo. Merece parabién el gesto de la Organización Internacional, pero se lamenta el autor de estas líneas de la dilación con que se ha producido: Si la Unión de Ciudades y Poderes Locales apunta a un asociacionismo técnico para cumplir una misión, en consecuencia, técnica, como es en verdad, es lástima que en el rodaje de la Unión puedan aparecer sombras que permiten derivar hacia consideraciones políticas, que siempre deben permanecer escrupulosamente apartadas de una organización que, aparte de postular un apoliticismo bien recibido, no debe ver coartada su eficacia por ninguna consideración que pueda perjudicarla.

En todo caso, y como españoles, hemos de congratularnos ante esa llamada al Consejo Ejecutivo y ante esa decisión de editar la versión castellana del órgano mensual escrito de la Unión, que ensanchará de manera indudable el ámbito de cooperación del organismo. Principio quieren las cosas. 
REVL-1979, núm. 202. RUIZ DEL CASTILLO Y DE NAVASCUES, CARLOS-ENRIQUE. EL CONGRE...

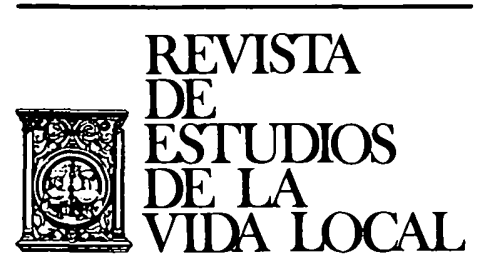

\section{ESTADISTICA}


REVL-1979, núm. 202. RUIZ DEL CASTILLO Y DE NAVASCUES, CARLOS-ENRIQUE. EL CONGRE... REVL-1979, núm. 202. RUIZ DEL CASTILLO Y DE NAVASCUES, CARLOS-ENRIQUE. EL CONGRE... 